\title{
JOSÉ MARÍA LUIS MORA Y EL MODELO FEDERAL NORTEAMERICANO: INSPIRACIONES Y RETICENCIAS
}

\author{
José María Luis Mora and the North American Federal Model: \\ inspirations and reticence
}

\section{RESUMEN}

El siguiente trabajo aborda la influencia de Estados Unidos en el pensamiento político del doctor José María Luis Mora, quien es considerado uno de los intelectuales mexicanos más importantes del siglo XIX. Los objetivos fundamentales de esta investigación son, por una parte, dar a conocer sus percepciones sobre la experiencia angloamericana, y por el otro, demostrar que esta fue más determinante de lo que el clásico de Charles Hale propone al respecto.

Palabras claves: José María Luis Mora, Federalismo, Historia de las ideas, México, Estados Unidos, Pensamiento político.

\section{ABSTRACT}

The following work addresses the influence of the United States in the political thought of Dr. José María Luis Mora, who was considered one of the most important Mexican intellectuals of the 19th century. The fundamental objectives of this research are, on the one hand, to make known their perceptions about the AngloAmerican experience, and on the other, to demonstrate that this was more determinant than what Charles Hale's classic proposes about it.

Keywords: José María Luis Mora, Federalism, History of the ideas, Mexico, United States, Political thought.

\section{EDUARDO HODGE DUPRÉ \\ Doctor en Historia de América y candidato a Doctor en Relaciones Internacionales. Profesor \\ Universidad de los Andes, Chile. Correo electrónico: e.hodge.dupre@ gmail.com}

Artículo recibido el 19 de julio de 2019.

Aceptado el 9 de septiembre de 2019. 


\section{INTRODUCCIÓN}

En su clásico sobre el liberalismo mexicano, Charles Hale (1972: 11-12) señaló que José María Luis Mora fue "el mayor teórico del período prerreformista" y "el más significativo portavoz liberal de su generación". Años más tarde, Janet Burke (2007) aseguró que él había destacado no solo por su vocación democrática, sino también por el interés de que México superara el desorden y la violencia que lo venían sacudiendo desde los tiempos de la Independencia. En esa misma línea, Enrique Dussel (2009) reconoció que Mora fue sin duda "uno de los principales impulsores de la estructuración de la vida independiente". Este trabajo no abordará sus ideas liberales ni su trabajo político, ya que esa labor ha sido realizada admirablemente por estos y otros autores (Rojas, 2012). Su novedad más bien estará en presentar la imagen del federalismo estadounidense en la obra del doctor Mora, tema que Hale y otros mexicanistas han refutado categóricamente.

Hale planteó que, previo a la Reforma, los pensadores mexicanos habían experimentado una fuerte contradicción respecto a Estados Unidos: idealizaban sus instituciones políticas, admiraban su progreso material y anhelaban experimentar la misma igualdad y libertad que sus ciudadanos; no eran pocos los que estaban convencidos de que el éxito histórico del vecino país se debía a su sistema político, basado en la ideología liberal y materializado en su derivación federal. Pero estas perspectivas coexistieron con una invariable tradición de conflictos, derrotas y usurpaciones territoriales que condicionaron las relaciones entre ambas naciones, a tal punto de producir fuertes desconfianzas que trascendieron en el tiempo. Este pasado ha hecho que pensadores y políticos mexicanos objeten todo tipo de influencias provenientes del vecino país. Una prueba de esto se puede encontrar en el periódico local $E l$ Federalista, del 3 de febrero de 1872:

Podría existir en el corazón de los mexicanos, y quizá exista adormecido, algún amargo, pero natural sentimiento hacia nuestros vecinos del norte. Mas ya sea por algún rasgo del carácter nacional, ya sea por la acción del tiempo que engendra conformidad o paciencia ante los hechos consumados, ya por las vicisitudes políticas 
que tanto han preocupado y distraído los ánimos, o ya por cualquier otra causa, los mexicanos o la mayoría de los mexicanos, lejos de demostrar de alguna manera ese amargo sentimiento, han asimilados sus instituciones a las de los Estados Unidos, a costa de inmensos sacrificios; han cooperado a la defensa de la Unión americana, resistiendo la intervención francesa y el Imperio; han mostrado fraternales disposiciones hacia los ciudadanos americanos, recibiéndolos generalmente como amigos, y por último, México, por medio de su gobierno, ha celebrado tratados que estrecharán más y más las relaciones de comercio y amistad entre ambos pueblos, sin que hasta ahora pueda de modo alguno echársenos en cara una falta o violación de esos tratados.

Es cierto que Hale reconoció que Mora había admirado las condiciones de Estados Unidos, y para ello citó un pasaje de Obras Sueltas, donde el mexicano había sostenido que dicha nación "había hecho la gloria y la prosperidad de un modo firme y estable" (Mora, 1837: 24). Sin embargo, esto no bastaba para para el historiador norteamericano, porque en realidad: i) el modelo norteamericano había figurado muy poco en los trabajos del guanajuatense; ii) su verdadera inspiración era el sistema francés; iii) George Washington fue situado al margen de su contexto social e institucional; iv) Estados Unidos había desaparecido virtualmente de sus escritos reformistas a partir de 1830 ; v) fue más bien indiferente al modelo norteamericano y llegó al punto de afirmar que Mora dedicó toda su obra a diferenciar los modelos mexicano y estadounidense (Escobar, 2003: 33); vi) que los métodos que buscaba para efectuar la reforma en México no los había hallado en el país vecino (Hale, 1972: 210-220).

Distinto a lo postulado por Hale y por Joseph Contreras (2009: 64), el siguiente trabajo busca demostrar que, a pesar de haber mirado con bastante desconfianza a sus vecinos del norte, el doctor Mora sí se inspiró en el ejemplo federal de Estados Unidos al momento de pensar el proyecto institucional mexicano (Sherman (1997) es uno de los pocos en reconocer que el teólogo estaba interesado en seguir la experiencia norteamericana). Y para demostrar esto, se analizarán los escritos que redactó entre 1824 y 1848 , entre los cuales figuran documentos políticos, periodísticos y correspondencia. Solo así se podrá llegar íntegramente a sus posturas intelectuales, públicas y privadas. 


\section{RASGOS BIOGRÁFICOS DEL DOCTOR MORA}

José María Luis Mora nació en el estado de Guanajuato el 12 de octubre de 1794. Al igual que otros pensadores de su época, destacó en diversos ámbitos: fue sacerdote, político, periodista e historiador. Obtuvo la Licenciatura en Teología en el Colegio San Ildefonso y el doctorado en la misma disciplina en la Pontificia Universidad (Paoli, 2014). En 1821 redactó el Semanario político y literario, y participó activamente en diversos medios, como El Sol, La Libertad, El Observador y El Indicador. En cada uno de estos difundió su posición liberal y promovió la necesidad de instaurar y fortalecer un régimen republicano. En 1824 fue diputado por el Congreso Local del Estado de México y en 1833 electo representante de Guanajuato para el Congreso Nacional (Téllez y Estrada, 2014).

Defensor de la educación laica y de acceso universal, colaboró con las reformas educacionales impulsadas por la primera presidencia de Gómez Farías (1833-1835). El principal objetivo de Mora en este ámbito era conectar la educación con las virtudes cívicas y legales, pues estaba convencido de que la organización nacional era imposible con ciudadanos ignorantes y desinformados (Dussel, 2009: 610). En parte, esta postura era una muestra de su anticlericalismo; Mora rechazaba toda posibilidad de que la Iglesia mexicana incrementara sus poderes políticos, sociales y económicos. En este mismo contexto redactó importantes obras, como El Catecismo político de la Federación Mexicana y Disertación sobre la naturaleza y aplicación de las rentas y bienes eclesiásticos. Cuando Gómez Farías fue desafectado del poder, huyó hacia Europa (Beorlegui, 2008).

Al tiempo después, publicó dos textos de suma relevancia: México y sus revoluciones (1836) y Obras sueltas (1838). De regreso en México, Mora continuó escribiendo a favor de la libertad y de la federalización del país. Durante el segundo gobierno provisional de su amigo Gómez Farías, fue nombrado Ministro Plenipotenciario en Londres, pero, al poco tiempo, y en compañía de una mujer que le cuidaba, falleció el 14 de julio de 1850 en la ciudad de París. La importancia de Mora para la historia mexicana es 
incuestionable. Muchos consideraron que su obra contenía los fundamentos del proceso de organización nacional. Al menos así quedó registrado en la obra de Francisco Zarco, fuente indispensable para conocer los detalles de la discusión parlamentaria que sancionó la Constitución de 1857. Escobar afirmó en esta línea que dicha carta fundamental "y, sobre todo, las Leyes de la Reforma, vienen a ser el corolario de las luchas del partido liberal y el triunfo de definitivo de las ideas del doctor Mora" (Escobar, 1974: 308). En todo esto descansa la razón de por qué es tan importante conocer su pensamiento al momento de estudiar el federalismo mexicano (Arnaiz, 1934).

\section{MORA Y LA ORGANIZACIÓN NACIONAL}

Es habitual encontrar en las obras de Mora comentarios alusivos al caos que había reinado en México después de la Independencia (“desorden republicano" en palabras de Carmagnani y Vázquez (1994: 39)). Y ello no era una exageración ni menos una utopía, pues él mismo había vivido en carne propia los distintos movimientos revolucionarios ocurridos en el país (González, 1984). El camino recorrido desde 1821 en adelante estuvo marcado por las luchas de poder, conspiraciones y conflictos internacionales (primero con España, luego con Estados Unidos), los que, sumados a la enorme y discordante variedad de caudillos, llevaron al país a una irremediable inestabilidad política y social que demoró el proceso de organización nacional (Velasco, 1967). Algo se había avanzado con la Carta de 1824, pero todo volvió a foja cero cuando fue derogada. Fue en este contexto donde Mora (1986a, p. 16) señaló que México todavía se encontraba en "estado de naturaleza". Su experiencia lo llevó a pensar que "las revoluciones políticas, o por mejor decir los síntomas del desorden y de la anarquía destruyen la prosperidad pública" (Mora, 1837, p. 150), cuestión clave para levantar los cimientos de la República.

El continuo, versátil y alborotado contexto político llevó a Mora a pensar en fórmulas que ordenaran al país en todas sus dimensiones. Creía que, "como la administración que sucedía era siempre peor y más ruinosa que la 
que la había precedido, la nación se precipitaba de abismo en abismo" (Mora, 1986a: 270). Durante 1830 logró convencerse de que las garantías ciudadanas contenidas en la Carta de 1824 debían ser restablecidas, pues era el único antecedente que tenían los mexicanos para promover el estado de derecho. Sostuvo que "con malas leyes ninguna nación puede progresar", por lo que era urgente instaurar un cuerpo legal que estuviera en concordancia con las circunstancias políticas de aquel momento (Mora, 1837: 271). En otro pasaje había asegurado que "el más firme apoyo de las leyes es aquel convencimiento íntimo que tiene todo hombre que los derechos que le son debidos y de aquel conocimiento claro de sus deberes y obligaciones hacia sus conciudadanos y hacia la patria" (Mora, 1837: 104). En esta frase sustentaba el motivo para fortalecer la educación y las virtudes morales, pues para alcanzar "la felicidad de todos, es indispensable esparcir hasta la más pequeña choza los rayos de luz que vivifican el espíritu" (Mora, 1827: 68).

Los desórdenes también incidían en la administración nacional. Dedicado a encontrar las posibles causas del caos, el doctor Mora llegó a la conclusión de que todo se debía a las "sombras del despotismo" heredadas de la época colonial. Pensaba que el "espíritu de partido" y los caudillismos que controlaban los Estados y territorios habían "desmembrado" políticamente al país y obstaculizado su cohesión. Según el autor, los poderes locales habían destruido el orden social, sobre todo porque tenían el control absoluto de las unidades, a través de facultades excesivas que los convertía en verdaderos “tiranos". Todo esto debilitaba la nación, puesto que rompía los vínculos que natural e históricamente unían a los Estados, pasando por alto los deberes impuestos por el Congreso y alterando lo que Mora llamaba "la convivencia pública", que "nunca más que ahora exige la unión y la concordia de todos los miembros y secciones de la nación mexicana" (Mora, 1986a: 14).

A pesar de su afán federativo, Mora sabía que no era fácil unir las voluntades particulares en un territorio tan amplio, diverso y desmembrado. En él, cada región tenía sus propias tradiciones históricas, políticas y económicas. En esta realidad las tensiones entre ellas quedaban al desnudo. Es por eso que el doctor Mora (1986a: 15) recomendaba que, entre las provincias asociadas, 
"se eligiesen de común acuerdo ciertos arbitrios, que decidiesen estas controversias por ciertas reglas generales que ellos mismos estableciesen, y a las cuales estuviesen las partes en obligación de sujetarse". Se esperaba que las partes dirimieran sus controversias a través de ciertas reglas generales que ellas mismas acordaran, establecieran y obedecieran, porque de modo contrario, "volverían a entrar en el estado bárbaro de la naturaleza de que habían intentado salir" (Mora, 1986a: 15). Es por eso que el federalismo, la unión de partes autónomas que conforman un proyecto nacional, pasaba a ser el medio necesario para transitar de lo antiguo a lo moderno, de la anarquía a la conciliación. Más adelante insistió:

Nada se habría todavía conseguido con esto, si cada particular pudiese resistir por el uso de su fuerza la regla general y la aplicación que se hiciese de ella, pues en este caso volvería a establecerse el imperio de la fuerza y con él todos los desórdenes que ésta produce; fue, pues, necesario organizar una fuerza pública, que hiciese cumplir a cada uno los pactos celebrados, y entrar en los deber que ellos imponen (Mora, 1986a: 15).

El guanajuatense estaba persuadido de que el sistema federal "era la forma de gobierno más perfecta y sencilla después de establecida”, pero también estaba consciente de que era "el más complicado al tiempo de organizarse, y la más sujeta a roces y colisiones, principalmente en una nación que ha estado unida bajo la presión violenta del despotismo" (Mora, 1986a: 53). Esta percepción era el fruto de su propia experiencia, pues no solo ponía en evidencia su más fiel interés por el federalismo, sino también demostraba que la organización de México sería lenta y no exenta de contrariedades. Mora conoció de cerca las distintas pugnas entre patriotas y realistas, liberales y conservadores, federales y centralistas. Había visto con sus propios ojos las heridas ocasionadas por los enfrentamientos internos de la nación que, al menos en el corto plazo, parecían irreconciliables. Inspirándose en la obra de Rousseau, indicó tenazmente:

El tiempo en que se constituye un Estado, es semejante al de formarse un batallón, el menos capaz de resistencia; si mejor se resiste en un desorden absoluto, que en el momento de fermentación donde cada uno cuida de su puesto y no del peligro; si 
es verdad, como él mismo continúa, que el estado se ve infaliblemente arruinado en el caso de que sobrevenga una guerra, un hambre, una sedición (Mora, 1986a: 53).

Contrario a lo propuesto por Hale (1972: 310-311), que los métodos y las teorías "debían buscarse en la Europa continental, cuyas tradiciones sociales e institucionales eran más análogas a las de México", Mora (1986a: 164) consideraba que el viejo continente había perdido la importancia de antaño. El caos y las contradicciones que provocaron los movimientos de la década de 1820 y 1830 lo llevaron a buscar otros referentes. Mora, como otros intelectuales de su época (Mier y Zavala según Trejo (2001)), optó por mirar hacia Estados Unidos, a pesar de hacerlo con cierta desconfianza. Incluso previo a la escisión de Texas, la diplomacia norteamericana provocaba en él algunas suspicacias. Pero esto no bastó. Pensaba ciegamente que las instituciones norteamericanas eran exitosas y fácilmente replicables en México. En 1837, cansado del desorden, de la "falta de respeto al decoro público", señaló que era fundamental ver "las ideas de políticas dominantes en cada uno de los principales pueblos del universo y cómo ellas han contribuido a su prosperidad o decadencia, para lo cual daremos noticia de sus Constituciones y de la clase de gobierno que las ha regido" (Mora, 1837: 5). En este punto dejaba en claro que era necesario considerar otras experiencias, como la norteamericana. En otro texto señaló al respecto:

Los Estados Unidos del Norte son el fundamento de la respuesta afirmativa, pues esta nación sin semejante facultad -Mora se refería al poder del gobierno central en algunas materias administrativas-, no sólo está regida, y muy bien por el sistema federal, sino que precisamente ha sido la que lo inventó, y ha probado con su ejemplo este modo de gobernarse los pueblos, no debe contarse en el número de las quimeras (Mora, 1837: 245).

Cuando Mora hablaba de las "ideas políticas dominantes", se refería principalmente a las norteamericanas (similar a lo propuesto por Escobar (1974: 33)), aunque en varias ocasiones mencionó el valor de la experiencia inglesa como ejemplo de libertad. Y para fortalecer sus argumentos, Mora no recurrió a los grandes teóricos institucionalistas de aquel país. Si bien conoció 
y leyó las obras de Tocqueville, Hamilton, Madison y Jay, lo cierto es que prefirió quedarse con la experiencia de George Washington, a quien concibió como el líder que hábilmente había aplicado las grandes teorías políticas a la realidad. El general independentista había logrado el orden interno de las colonias, la organización del país en un contexto de constantes tensiones y la instauración de un gobierno fuerte cuya capacidad consideraba la divergencia del territorio, básicamente lo mismo que él aspiraba para México. Al respecto señaló:

Bastaría la autoridad de este grande hombre, tan profundo político como amante imparcial de las instituciones republicanas y de la libertad de los pueblos, para que todos los gobiernos que deseen sinceramente poner a salvo los derechos de las naciones y verse libres de facciones sediciosas, se empeñasen en proscribir esos semilleros de anarquía y del desorden, esos centros de proyectos facciosos y esos clubs usurpadores de la autoridad pública (Mora, 1837: 307).

El doctor Mora consideraba que Washington había precipitado la llegada de los tiempos modernos. Admiraba su papel durante la guerra de independencia, su compromiso con la libertad y, sobre todo, su capacidad para resolver los problemas de la organización nacional, especialmente aquellos derivados del consenso que tuvieron que alcanzar las colonias una vez finalizada la lucha emancipadora. Al igual que en México, esta tarea no había sido nada de fácil, pues la diversidad de intereses provinciales provocó rivalidades que amenazaron con romper los acuerdos alcanzados. De hecho, el mismo Mora señaló que la designación y luego aplicación del sistema de gobierno había producido tensiones bastante complejas, en tanto que "los hábitos de un pueblo suelen ser contrarios al sistema que adoptó", sobre todo en casos "que han pasado súbitamente del absolutismo a la libertad" (Mora, 1827: 219). Pero Washington tuvo la habilidad de instaurar un sistema de gobierno que paralelamente conformaba un proyecto nacional sin transgredir la autonomía de las colonias, por medio de la valoración de textos legales que prevenían su inviolabilidad. En las palabras de guanajuatense:

Contra el torrente de las preocupaciones dominantes por aquella época en el país, 
sostuvo y consiguió la adopción de la nueva Constitución. Así fue como consiguió este hombre verdaderamente grande la fama de un profundo político, el aprecio general de todo el mundo civilizado, si la prosperidad de su patria y una gloria eterna e inmortal. Si las circunstancias muchas veces destruyen o consolidan los sistemas de gobierno y que un hombre suele ser una circunstancia, es el caso de Washington. En efecto, los Estados Unidos del Norte acaso no hubieran llegado al estado en que se hallan, si este hombre singular y su política no hubiesen sido para ellos la circunstancia más favorable que puede presentarse a un pueblo nuevo, para la consolidación de sus instituciones (Mora, 1986a: 298).

Pero adicional a lo anterior, Mora resaltó el interés de Washington por establecer un gobierno fuerte, capaz de convocar la diversidad y, a partir de ella, montar un proyecto nacional vigoroso (en parte, esto rompe con la idea de que el federalismo norteamericano es un sistema con un Ejecutivo débil o que otorga una autonomía casi total de sus unidades estatales). Algo así como el mismo modelo que debía seguir el México si quería ordenar el caos interno, establecer una reglamentación inquebrantable y luego cautelarla con instituciones políticas duraderas. En 1830, Mora (1830: 443) señaló que, sin fuerza, ni energía ni autoridad, era imposible "contener las asonadas populares ni garantizar a los particulares sus derechos naturales". Ante la interrogante “ ¿si el gobierno carece de energía y autoridad para hacerse obedecer y poner a cubierto de las persecuciones populares y del odio, siempre temible de los partidos, las personas y bienes de los ciudadanos?", su respuesta fue categórica: "ninguno ciertamente". En esta situación, decía Mora "la seguridad personal desaparece y con ella todos los bienes que puede apetecer el hombre, cuando el poder ejecutivo carece de aquella fuerza que debe gravitar sobre los particulares".

Un aspecto que llamó la atención de Mora fue que los norteamericanos supieron combinar muy bien el centralismo con el respeto acérrimo a las soberanías locales (Mora, 1830: 446). Por ello, después de haber conseguido la independencia, y temeroso de "caer en un gobierno despótico", establecieron "uno que contaba de algunos delegados de los mismos Estados", de modo que existiera un equilibrio en la estructura de poder. Ante esto, Mora quiso conocer los resultados, mostrando su lado más utilitarista (González, 2000). Para dominarlos mejor, recurrió a la obra de David Ramsay, Life of 
George Washington, quien había presentado a un Washington "decidido por el federalismo y principios liberales." Apenas terminada la guerra de independencia, el líder revolucionario "entró en la clase de simple ciudadano", pero sus compatriotas comenzaron a "disfrutar de las ventajas que debería proporcionarles una paz en el gobierno revolucionario." Sin embargo, los acontecimientos habían mostrado, según Mora, la "insuficiencia del gobierno para promover la felicidad pública y conservar la dignidad nacional", pues no tenía las potestades ni instrumentos básicos para satisfacer a los acreedores ni para inspirar respeto en las potencias extranjeras. Luego prosiguió:

El comercio disminuyó, la propiedad fue despreciada y el crédito aniquilado. Los amigos de la libertad e independencia empezaron a perder las lisonjeras esperanzas que habían concebido en los principios de la revolución: en los cinco o seis años que siguieron a la paz, la república naciente fue decayendo de día en día. Este es el estado infeliz a que llegaron nuestros vecinos con el gobierno de muchos; mas luego que éste cambió y se puso un presidente, la nación hizo progresos asombrosos hasta llegar en menos de medio siglo a rivalizar con las potencias de Europa por su grandeza y prosperidad (...) Siempre que el gobierno ha carecido de unidad por haberse colocado en muchos, le ha faltado igualmente la autoridad y energía sin la cual es imposible mantener la tranquilidad interior ni hacer respetable a la nación en lo exterior. La política es una ciencia experimental (Mora, 1986a: 62).

En esta misma línea, el guanajuatense llegó al extremo de señalar que la federación dependía de un gobierno central vigoroso. En 1837 afirmó algo muy similar al clásico de Hamilton, Madison y Jay: "Crear un gobierno fuerte que la pueda sostener contra las invasiones extrañas, de entablar relaciones políticas y mercantiles con las potencias extrañas y de combinar los intereses particulares con el público", de tal manera que "se eviten las convulsiones interiores, germen y origen de la guerra civil y de la anarquía" (1837: 10).

Esto lo pensó porque las circunstancias así lo ameritaban: luchas de poder, amenazas extranjeras y caudillismos que ponían en constante peligro el proyecto nacional. De todos modos estaba consciente de que la federación sería perseguida por los sectores conservadores, que la creían inaplicable a la realidad mexicana. De hecho, estos consideraban que la Constitución de 1824 era una muestra más de la desorganización imperante. Para Mora, esta 
percepción revelaba los patrones culturales de la colonia, inclinados hacia las formas centralistas o unitarias, que seguían vigentes en los tiempos modernos. Sin embargo, a pesar de estas contrariedades, estaba empecinado con la federalización del país. Llegó a sostener que lo normado en 1824 no podía volver atrás: "cada artículo de la Constitución general y de los Estados que se dicta, es un clavo que remacha y asegura el sistema adoptado" (Mora, 1986a: 64).

\section{UN FEDERALISMO VIGOROSO}

En todo momento, Mora pensó que México estaba hundido en una indefectible crisis institucional. De hecho, al poco tiempo de haber sido sancionada la Carta de 1824, declaraba con cierta angustia que "era necesaria muy poca filosofía y ningún conocimiento de la marcha de las naciones para persuadirse que hay fuerza capaz de hacer retroceder a un pueblo de un sistema que ha adoptado libremente con aplauso y entusiasmo general" (Mora, 1986a: 64); solamente bastaba que la ley se hiciera "perniciosa a los pueblos". Es por esto que el teólogo mexicano proponía un poder Ejecutivo poderoso, que "tuviera la fuerza necesaria para hacer respetar en lo exterior y garantizar en lo interior las personas y bienes de los ciudadanos". Estaba persuadido de que las fuerzas antifederales no detendrían su causa: "hay algunas personas, por otro lado muy apreciables" que, sin asumir los nuevos tiempos, estaban favoreciendo un rápido retorno a las instituciones del pasado, valiéndose “de todo su crédito e influjo, que es grande, para desacreditar los congresos de los Estados”. Sin embargo, “estos pequeños esfuerzos nada pueden contra la masa de una nación” (Mora, 1986a: 64). Mirando nuevamente hacia el norte, señaló:

La mejor política, dice Washington, es la buena fe; haya algunos en hora buena que piensen sacar partido para el centralismo del gobierno de uno; pero las instituciones producen los efectos de su naturaleza y no los que los hombres se proponen al dilatarlas; los enemigos del sistema, si los estados no contribuyen a desacreditarlo, y tienen bastante prudencia para precaverse de sus ataques insidiosos, se hallarán enteramente burlados. Estas son las reflexiones que presento (...) a fin de que 
promuevan que el Supremo Poder Ejecutivo de la nación resida en una sola persona, aunque con las limitaciones que tiene el presidente de los Estados Unidos y la sujeción al Senado que previene la Constitución de aquella nación (Mora, 1986a: 64-65).

Entre las formas de gobierno, el doctor Mora se inclinaba por la República. Estaba convencido de que "el siglo actual no es de reyes para la América" (Mora, 1986a: 323), pues "los motivos de su independencia, su distancia de los tronos de Europa, la lucha entre los reyes absolutos y los pueblos, las ideas vigentes contra los monarcas, el ejemplo de una república americana consolidada y floreciente [refiriéndose a Estados Unidos]" (Mora, 1986a: 347), hacían imposible otra alternativa de gobierno para México y América Latina. Pero también señaló que a esta había que añadirle "la palabra federal", que "empezaba a ser algo". El problema es que este "algo" se había tornado "tan envuelto en dificultades, tan rodeado de resistencias y tan en oposición con todo lo que se quería mantener, que no se necesitaba mucha perspicacia para prever la lucha no muy remota entre el progreso y el retroceso" (Mora, 1986a: 64-65) que, en otras palabras, no era sino lo moderno y lo antiguo respectivamente. Como lo afirmó el mismo Mora, el vecino norteamericano encarnaba esos ideales de progreso y modernización:

En los principios de este mismo siglo XIX, mientras en Estados Unidos hacía más de medio siglo que Franklin había inventado el pararrayos, y hacían gran progreso teórico y práctico las ciencias filosóficas modernas, en la Nueva España se escribía e imprimía un libro contra el sistema de Copérnico; y mientras en los Estados Unidos Juan Fulton se ocupaba de inventar los buques a vapor, en la nueva España se continuaba escribiendo e imprimiendo libros sobre milagros [en 1837 sostuvo que Estados Unidos había logrado una "paz duradera" y rápidos progresos, alcanzando un "nivel de primera potencia" y un estatus de "rico, industrioso y respetable"] (Arnaiz, 1934: 38).

Es posible sostener que Mora veía a Estados Unidos como una realidad similar a la mexicana, que solo progresó gracias al buen funcionamiento de sus instituciones políticas. El guanajuatense planteó que la situación estable de los pueblos americanos, entre los que se encontraba su país, era razón suficiente para sancionar "Constituciones mucho más perfectas que las formadas en 
Europa", argumentando que "la Constitución de los Estados Unidos del norte de América no sólo ha sido altamente elogiada por los escritores más célebres de la Europa, sino que también ha hecho la gloria y prosperidad de un modo firme y estable en el pueblo más libre del universo" (Mora, 1986a: 298). El poder político de los vecinos había llegado a tal nivel, que Mora lo comparaba con la supremacía naval británica y la manufactura francesa. No dejó de llamarle la atención que todo esto se había dado "en el corto espacio de medio siglo, cuando estas naciones [refiriéndose a las europeas] no han podido llegar al grado de prosperidad en que se hallan sino después de centenares de años, y de terribles oscilaciones y vaivenes políticos" (Mora, 1986a: 298).

En 1827, Mora (1837: 24-25) deseaba que México "aproveche la feliz oportunidad que se le ha venido a las manos para constituirse con paz y tranquilidad". Y para lograr este cometido era fundamental "poner a la vista de nuestros conciudadanos las constituciones de los pueblos más célebres", dentro de los cuales la norteamericana gozaba de un esplendor único. De todos modos, aseguró que era necesario realizar un análisis minucioso de todas ellas, y así hacer los reparos y reflexiones que "nos parezcan más oportunas; pero antes de que nuestro propósito tenga efecto respecto a las Constituciones angloamericana y francesa que acabamos de publicar", era clave delimitar sus aspectos generales: “debe contenerse la autoridad de todo gobierno, sin sujetarnos ciegamente a las doctrinas de los publicistas de Europa, y atendiendo solamente al fin de las instituciones sociales, y a la naturaleza del contrato que une a los pueblos con los gobiernos" (Mora, 1837: 24-25).

Pero a lo anterior se suman algunos temas que Mora asoció a la experiencia norteamericana, y que merecen atención especial. El primero de ellos era la preocupación por la soberanía nacional que, según él, los angloamericanos tenían resuelto desde los tiempos de la independencia. Al respecto señaló que "nuestra población es muy superior a la de varios Estados independientes de Europa y sin disputa es duplo de la que contaban los Estados Unidos al pronunciarse independientes", situación "que hizo temblar a la nación británica y frustró enteramente todos los planes de subyugación que ésta tenía con respecto a sus colonias americanas" (Mora, 1837: 21). 
Esta nación, "cuya fuerza marítima es la mayor y más formidable que se ha conocido en el universo, no pudo sujetar a tres millones de paisanos desarmados, destituidos de conocimientos militares y en terreno que por ser el menos fértil de todo el continente", y solo lograron alcanzar su estadio a punta de "cohesión" y "compromiso" (Mora, 1837: 21). En este punto, Mora resaltó dos materias fundamentales: por una parte, los beneficios producidos por la unión de las fuerzas y, por otra, la importancia de contar con un aparato institucional debidamente configurado.

El segundo tenía que ver con aspectos económicos. El guanajuatense indicó que el "origen más fecundo de nuestros males en todo el periodo que ha transcurrido de la Independencia acá, ha consistido en la administración de la hacienda pública, especialmente en el gobierno federal" (Mora, 1986a: 181). Aseguraba que esto se resolvía ajustando las piezas del sistema de gobierno imperante, fortaleciendo la representación política, brazo estatal que debía "acordar las contribuciones por medio de los representantes de la nación, y tomar cuenta de la inversión de los caudales públicos” (Mora, 1986a: 181). Consideraba que la libertad y la gobernabilidad eran factibles en la medida que el poder central tuviera solvencia fiscal. Esta idea "se ha hecho un axioma de legislación constitucional en todos los pueblos libres [aludiendo claramente a Estados Unidos]. Nosotros, sin embargo, hemos visto este punto cardinal con el mayor abandono". Este problema se resolvía con presupuestos anuales que cubrieran "todos los gastos nacionales y rendir la cuenta de eso". La noción de "gasto nacional" es una muestra fehaciente de las perspectivas federales del doctor Mora. De hecho, en otro documento analizó pormenorizadamente la economía federal, destacando los siguientes puntos:

i) el compromiso y obligación de las unidades miembro de normalizar su situación interna para que puedan colaborar estrecha y sistemáticamente con el gobierno central; ii) que también corrijan las malversaciones públicas; iii) evitar los aislacionismos, sobre todo en materia de gastos; iv) que la no contribución a la hacienda federal, llevaría a una ruina indefectible, "porque entrará el desorden, para el que por desgracia hay tantos elementos y se hacen tantos esfuerzos."; v) pidió sobrellevar "todos con igualdad proporcional las cargas que la fatalidad nos 
ha impuesto" (Mora, 1986a: 181).

La admiración de Mora por la experiencia norteamericana convivió bastante bien con su postura anti-intervencionista. A finales de la década de 1820, dio las primeras señales de lo que propondría años después, cuando las relaciones con Estados Unidos alcanzaron su punto más álgido, primero con la separación de Texas y luego con la guerra de 1847. Y para repudiar la política expansiva de algunas naciones extranjeras, Mora recurrió nuevamente a Washington, esta vez citando uno de sus discursos dirigidos al pueblo al momento de su retiro público. En aquel momento recomendó “con el más vivo empeño la importancia y necesidad de evitar la influencia de los gabinetes extranjeros en los negocios domésticos." Para Mora (1986a: 284-286), Washington era una autoridad:

Bastaría que este grande hombre, este profundo político, este héroe de la razón y de la filosofía hubiese sentado esta máxima como base de las operaciones de todo gobierno libre y como regla de que no deben separarse los que quieran con sinceridad y buena fe consolidar un sistema republicano, para que los pueblos y los que presiden a sus destinos viesen con la mayor desconfianza las sugestiones de los gabinetes extranjeros, escuchasen con prevención sus proposiciones y estuviesen alerta sobre la conducta de sus ministros.

El argumento de Mora (1941: 71) radicaba en que las naciones habían padecido este mal porque sus gobiernos no se habían "convencido de que el interés verdadero por la prosperidad de un país no puede existir fuera de él". Pensaba que las potencias extranjeras no tenían en sus vecinos otros intereses que satisfacer sus propias necesidades, y que la mayoría de las veces esta conducta perjudicaba el bienestar local. Por ello sostuvo que "buscar pues la dirección de los propios negocios en un gabinete extraño, o tolerar la influencia de éste en las autoridades y ciudadanos del país, no sólo es la mayor prueba de imbecilidad de un gobierno", sino que también "el mayor de todos los crímenes y el cargo más fundado para derrocarlo y hacer que sufra el condigno castigo de tamaña maldad." Mora (1837: 186) creía que, con esto, los gobiernos traicionaban a sus pueblos, pues destruían lo más sagrado, que 
era la independencia nacional, vista como "el más precioso de sus intereses y los entrega atados de pies". Defendió fuertemente este punto, considerando que el motor para alcanzar la prosperidad y bienestar material se hallaba en la soberanía y en la libertad nacional. Sin decir que se refería a Estados Unidos, señaló:

La táctica de los gabinetes modernos que tienen pretensiones sobre sus vecino es más insidiosa y consiste en apoderarse de los que gobiernan, en organizar facciones y partidos que puedan servir cuando se tenga por necesario, y en soplar el fuego de la discordia que excitando pasiones populares relaje los vínculos que unen a los ciudadanos entre sí y con su gobierno y debilite a los pueblos por su descontento y falta de unión, hasta ponerlos en estado de que puedan recibir la ley y el yugo de aquel que quiera imponérselos (Mora, 1986a: 285).

A lo largo de la obra de Mora, el único dato que podría poner en duda su interés por la experiencia norteamericana fue un análisis que hizo sobre los derechos de ciudadanía en la República, y que data de 1830. En aquel documento, señaló que "nuestra federación se ha hecho de un modo inverso a la de los Estados Unidos del Norte de nuestro continente", pues en "aquélla partió de la circunferencia al centro", mientras que en México se hizo "del centro a la circunferencia". En el vecino país, "los Estados crearon al gobierno federal; en la nuestra el gobierno federal dio existencia política a los Estados". También, "en el norte, muchos Estados independientes se constituyeron en una sola nación; en México, una nación indivisa y única, se dividió en Estados independientes hasta cierto punto". Después de suponer estos principios, Mora (1830: 217) se preguntó: “¿quién podrá dudar, que si en el norte los Estados dieron la ley al gobierno federal, en México el gobierno federal debe dársela a los Estados? Ahora bien, ¿qué cosa más justa, oportuna y convenientes para la aplicación de este principio que los derechos de ciudadanía?", respondiendo:

Los miembros actuales de esta sociedad que se llama República Mexicana, primero han sido miembros de la nación y perteneciendo antes a ésta que a los estados; (...) Luego es fuera de duda, que éste lo deben recibir, primero, el cuerpo entero de la sociedad, que de las fracciones erigidas posteriormente en estados independientes. Luego si los estados pueden exigir condiciones para que sus respectivos habitantes disfruten en su territorio de la voz activa y pasiva, éstas han de ser, supuestas ya las 
que los poderes supremos hayan fijado para el ejercicio del derecho de ciudadanía en toda la República, o, lo que es lo mismo, que el derecho de estos debe presuponer al de aquella y lejos de contrariarlo, debe subordinarse a él.

Esta distinción no debe poner en duda sus planteamientos federales ni menos sus deseos de construir un proyecto político de acuerdo con el ejemplo norteamericano. En sintonía con lo propuesto por Mena (1958: 44-57), que Mora era un "convencido de la bondad del sistema federal" y un "enemigo a muerte de toda idea central", es posible sostener que el teólogo, en ningún momento, pretendió desmarcarse de la experiencia estadounidense, pues solo le interesaba dejar en claro que entre ambos casos había una pequeña diferencia, y que tenía que ver con sus orígenes. Aclarar este punto era necesario por cuanto determinaba temas tan importantes como la ciudadanía, base de la representatividad, clave de la organización nacional y sustento del orden social y político de México. La posición de Mora (1986a: 426-427) era clara: su limitación y prolongación no eran contrarias a la libertad pública, como sucedía en uno de los pueblos "más libres que se conocen en el universo". Para comprobar esto, recurrió al caso norteamericano:

En efecto, en los Estados Unidos cuyas instituciones por su forma y carácter tienen más analogía con las nuestras, el Senado dura seis años y su renovación no coincide por lo común con la del presidente ni con la de la Cámara de Representantes. (...) además de que en aquella nación por sus circunstancias peculiares jamás hubo motivo de temer revoluciones, es sabido por regla bastante común, que hasta ahora no ha tenido sino dos excepciones en los Adams padre e hijo, que siempre se reelige por una vez al presidente, con lo cual viene a durar ocho años, cuando entre nosotros está prohibida la reelección. Además, es sabido que Jay y el famoso Franklin, uno de los defectos más graves que censuraron a la Constitución de su país, fue el de la corta duración del presidente. Así pues, esta falta en un pueblo morigerado y amigo del orden, y que la ha suplicado constantemente con la reelección, no ha podido surtir los mismos efectos que el nuestro, donde veinte años de revolución han destruido todos los hábitos del orden, de sumisión y obediencia, y donde no puede apelarse ni al arbitrio de la reelección, que está prohibida (Mora, 1986a: 426-427).

\section{MORA Y SUS DESVELOS INTERNACIONALES}

Pero en paralelo a la admiración por las instituciones norteamericanas, 
hubo un rechazo muy poderoso hacia la política exterior del vecino país. Esta conducta habría crecido con la guerra de 1847, cuyas consecuencias fueron consideradas por Mora como nefastas para el devenir de la nación. En una carta dirigida al general Santa Anna, señaló: “jamás me hacen desistir del cumplimiento de mi deber, que consiste en amontonar contra los Estados Unidos todos los embarazos y dificultades chicas y grandes que puedan venirme a la mente o que esté en mi poder suscitarles" (Mora, 1986a: 426-427). Y una de las formas que utilizó para realizar este cometido, fue gestionar con las potencias europeas la ayuda necesaria para repeler a las fuerzas invasoras que ya controlaban gran parte del país. Son conocidas las relaciones que estrechó con importantes personeros de Francia e Inglaterra, con el propósito de que intercedieran en el conflicto a favor de México.

Es pertinente subrayar que la preocupación de Mora se debía a cuestiones más trascendentales, como el interés de Estados Unidos por regiones que tenían recursos que favorecerían el progreso de México. En este sentido, en una de las cartas enviadas a Lord Palmerston, señaló que la resistencia general de su país de "abandonar una sola pulgada de su territorio a favor de la confederación norteamericana", debía darse "más viva y enérgica con respecto a la costa del oeste y será absolutamente insuperable respecto de los puertos de Monterrey y de San Francisco" (Mora, 1986a: 123). Luego acotó: "la providencia podrá acaso poner a México en la triste situación de no poder defender esa parte interesante de su territorio, pero si, lo que no es de esperarse, las cosas llegaren a otro Estado", nada llevaría a la autoridad mexicana a legalizar una "posesión violenta". En una misiva posterior, declaró al mismo ministro inglés: "SM preste su influjo moral para impedir que en ningún caso posible los Estados Unidos queden dueños de algunos de los puntos comprendidos entre el puerto de San Diego y el Cabo Mendocino en el territorio de nueva California" (Mora, 1986a: 126).

Estando en Europa, Mora se preguntó si a México le convenía o no venderle territorios a Inglaterra, y si ello haría más fácil la protección del territorio frente a posibles invasiones norteamericanas, cada vez más inminentes. "En efecto, esta situación es triste, tristísima, pero es inevitable" 
(Mora, 1986a: 140). Luego aseveró que las arremetidas de Estados Unidos hacia el territorio mexicano se debía a su "su constitución social, que los arrastra a ensancharse a expensas de sus vecinos, y en su estado político, que por ambiciones a la presidencia, combinadas con los intereses electorales y una popularidad exagerada", impulsaban empresas "aventuradas que tendrán siempre su efecto por el lado del sur o México" que, según el guanajuatense, era la más débil de las naciones que le rodeaban. Ante la incertidumbre que producía la vecindad con aquella nación, la solución que aparecía en escena no deja de ser interesante:

Así, pues, después de unos cinco o diez tratados, en cada uno de los cuales Estados Unidos habrá ganado terreno, la dificultad queda siempre en pie y muy notablemente agravada en cada uno de estos periodos, si una fuerza considerable, fija y permanente en los límites, no viene a poner término a estas tendencias invasoras que se reproducirán sin cesar. Si México pudiera organizar esta fuerza, que no consiste sólo en soldados, sino en instituciones e intereses, no habría necesidad de apelar a un tercero para obtener el resultado que se busca (Mora, 1986a: 140).

Mora veía con desesperanza cómo Estados Unidos se expandía a costa de su país durante la guerra de 1847. Que producto del enfrentamiento se perdían importantes territorios, y de paso se atropellaba la identidad nacional. Pero en todo ello Mora tuvo la lucidez de identificar la raíz del problema, que no era otro que el estado de las instituciones mexicanas, puntualmente las federales. Pensaba que la situación de México no era coyuntural, sino más bien el producto de un proceso histórico más amplio. Años antes, en una carta enviada a su amigo el doctor Gómez Farías, todo se había centrado en el caso de Texas, que también había producido algunas tensiones entre Estados Unidos, Francia e Inglaterra. Refiriéndose al primero de estos, señaló: "la fuerza expansiva de este pueblo, atrevido e insolente con el débil y a la vez sumiso y bajo con el fuerte, es vista con positivo y formal disgusto en estos países, y si en México se supiera sacar partido de estas disposiciones, se impediría semejante reunión" (Mora, 1986a: 211-212).

Mora pensaba que la pérdida de territorio era una muestra incuestionable de la fragilidad del sistema político mexicano. Con la finalidad de no repetir 
el error de Texas, el análisis de Mora fue claro: "actualmente sobre lo que es necesario tener el ojo abierto es sobre California: es necesario colonizarla lo más pronto con hombres de un pueblo de que México nada tenga que temer; este pueblo es el español”. El poblamiento de esta región generaría soberanía, lo cual permitiría contener los avances del invasor. Aseguró no importarle si estos provenían o no del extranjero, aunque los colonos sí debían ser españoles. Y los motivos de esto eran muy sencillos: similitud cultural y lingüística. Sabía que si esto no se concretaba, "antes de veinte años California es también perdida para México y después lo que sigue”. El guanajuatense creía que los ingleses no tenían predilección sobre ninguna forma de gobierno, mientras que los franceses deseaban establecer en México una monarquía constitucional. Él, sin embargo, mantenía sus "viejas ideas federalistas" (Mora, 1986a: 211-212). Esto se conecta muy bien con una de las cartas enviadas por él al gobierno de México en mayo de 1848:

Que la grandeza de una nación se medía no por el terreno que ocupaba, sino por el vigor y robustez de su constitución interior, y que para esta tenía México elementos que no se necesitaba más que alguna voluntad y constancia y una mediana inteligencia para constituir un razonable poder que hiciese frente a todas las eventualidades (Mora, 1986a: 188).

Las pérdidas de Texas y de los territorios del norte revelaban la inoperancia del federalismo mexicano. Mora, quien veía estos hechos con desazón, pensaba que la mutilación del territorio era producto de tres factores ciertamente contradictorios: i) el enfoque mismo de la Carta de 1824, más cercana a un modelo confederal; ii) su rápida derogación, que no le permitió consolidarse en el tiempo; iii) y la centralización de facto que los gobiernos sucesivos impusieron constantemente en el país, transformándose en verdaderas autocracias, como los gobierno se Santa Anna (Costeloe, 1996: 261). De hecho, en 1840 su amigo José María Gutiérrez hacía la relación entre el conservadurismo, el centralismo y la tiranía:

Por ejemplo, mientras los centralistas y federalistas están disputando acaloradamente acerca de las atribuciones del poder conservador y del gobierno con respecto a las 
resoluciones de aquél, se dice que se trabaja con alarmante apariencia de bueno y pronto éxito en favor de una dictadura, que suponen no se ha proclamado puramente par l'embarras du choix entre Bustamante, Santa Anna y Valencia” (García, 1906: $30)$.

Estos puntos no solo impedían un mayor control del territorio, sino también ponían en riesgo la autonomía de los Estados, cuestión que preocupaba a todos los actores centrales y regionales por igual. Es por eso que Mora reivindicaba la Constitución de 1824, pidiendo su reinstalación, ya que estipulaba la distribución del poder político en todo el territorio nacional. Solo así se podían ordenar las provincias y poner fin a esa revolución que parecía interminable. Dentro de todo, el apasionado teólogo quería demostrar, en el escenario internacional, que México era una república bien constituida. Si bien Gómez Farías fue más radical con este punto, no deja de ser interesante cómo el guanajuatense vinculó federalismo al orden y resguardo del territorio de amenazas externas.

\section{CONCLUSIONES}

No es sorpresivo que José María Luis Mora haya desconfiado tanto de la política exterior de Estados Unidos. Había experimentado en carne propia el conflicto que terminó separando Texas del territorio nacional; $y$, en su papel diplomático en Europa, pudo acceder a los pormenores de la guerra de 1847. Vio con sus propios ojos cómo los norteamericanos se apropiaban rápidamente del territorio nacional, en su mayoría zonas muy prodigiosas en recursos naturales. Pero, a diferencia de lo que han sostenido algunos estudiosos, eso no bastó para que Mora dejara de admirar la experiencia estadounidense. Es más, este trabajo demostró que el principal modelo que tenía el teólogo mexicano para la organización de México era precisamente Estados Unidos. Y no solo porque este había sido exitoso material e institucionalmente, sino también porque supo cómo ordenar su propia situación interna por medio de un gobierno central absolutamente vigoroso, el mismo que Mora deseaba replicar en su natal país. En otras palabras, Europa y su desconcierto dejaban 
de ser un paradigma, un camino, al menos para él.

El problema, es que seis años antes de haberse iniciado el constituyente, Mora había partido de este mundo; no alcanzó a ver la Constitución que tanto anhelaba, la que generaciones de mexicanos venían esperando desde los tiempos de la Independencia. Sin embargo, sus ideas habían calado profundamente en la mentalidad de aquella generación de liberales que deseaban — tanto como él- ver al país ordenado después de tanto tiempo subsumido en la violencia, intrigas e inseguridad, tanto nacional como internacional. Esa relevancia e influencia ha sido reconocida por múltiples intelectuales. Por ejemplo, el mismo Rabasa (2004: 187) lo situó entre los "más distinguidos, célebres y recordados" intelectuales que influyeron en la Carta de 1857, mientras que Téllez y Estrada (2016: 13) lo recuerdan como "el padre de las reformas liberales" que allanaron el camino para que México alcanzara la estabilidad. En efecto, recordar a Mora es recordar a uno de los artífices del México decimonónico.

\section{BIBLIOGRAFÍA}

Arnaiz, A. (1934) El doctor José María Luis Mora, 1794-1850: homenaje de la UNAM al reformador ilustre. México: UNAM.

- (1956) El Doctor Mota, teórico de la reforma liberal. Historia Mexicana del Colegio de México, vol. 5, N 4, (549-571).

Beorlegui, C. (2008) Historia del Pensamiento Filosófico Latinoamericano. España: Universidad de Deusto.

Burke, J. (2007) Nineteenth-Century Nation and Building and the Latin American Intellectual Tradition: A reader. Estados Unidos: Hackett Publishing Company Inc.

Carmagnani, M. (1994) La fundación del Estado mexicano: 1821-1855. Interpretaciones para una historia. México: Nueva Imagen.

Contreras, J. (2009) In the shadow of the Giant: the Americanization of Modern Mexico. Estados Unidos: Rutgers University Press.

Costeloe, M. (1996) La primera república federal de México (1824-1835). Un 
estudio de los partidos políticos en el México independiente. México: FCE.

Dussel, E. (2009) El pensamiento filosófico latinoamericano, del Caribe y “latino” (1300-2000). México: Siglo XXI.

Escobar, G. (2003). El liberalismo ilustrado del Dr. José María Luis Mora. México: UNAM.

Flores, Ó. (2003) Historiadores de México siglo XIX. México. Trillas.

Frahm, S. (2014) The Cross and the Compass. Freemasonry and Religious Tolerance in Mexico. Estados Unidos: Palibrio.

García, G. (1906) Papeles inéditos y obras selectas del doctor Mora, México: Vda de C. Bouret.

González, M. (2000) José María Luis Mora y la creación del Estado de México. México: Poder Legislativo del Estado de México.

_- (1984) José María Luis Mora: la formación de la conciencia burguesa en México. México: UNAM.

Hale, Ch. (1972) El liberalismo mexicano en la época de Mora, 1821-1853. México: FCE.

Lira, A. (1989) La recepción de la Revolución Francesa en México, 18211848: José María Luis Mora y Lucas Alamán. Relaciones. Estudios de Historia y Sociedad, vol. 10, № 40 (5-27).

Mena, M. (1958) Un clérigo anticlerical: el doctor Mora. México: Editorial Jus.

Mora, JML. (1827) Educación pública. El Observador de la República Mexicana. Tomo 1, México.

- (1830) Política sobre el Distrito Federal. El Observador de la República Mexicana. Tomo 3, México.

- (1837) Obras sueltas. México: Rosa. (1941) Ensayos, ideas y retratos. México. (1986a) Obras completas. México: SEP.

Paoli, F. (2014) Intelectuales, cultura y política. Intelectuales en México: de la Independencia a la Revolución. México: Keh.

Rabasa, E. (2004) La evolución constitucional de México. México: UNAM. 
Ramírez, J. (2004) Obra histórica. México.

Reyes Heroles, J. (1988) El liberalismo mexicano. México: FCE.

Rojas, R. (2012) Mora en París (1834-1850) un liberal en el exilio. Un diplomático ante la guerra. Historia mexicana, vol. 62, $\mathrm{N}^{\circ} 1$, México (7-57).

Sherman, J. (1997) The Mexican Right: the end of revolutionary reform, 19291940. Estados Unidos: Greenwood Publishing Grou.

Téllez, M. Estrada, R. (2014) José María Luis Mora. Un hombre de su tiempo. México: Instituto Nacional de Ciencias Penales.

- (2016) José María Luis Mora: un legislador en el Constituyente del Estado de México 1824-1827. Revista Mexicana de Historia del Derecho, N XXXIII, México: UNAM (173-207).

Trejo, E. (2001) Los límites de un discurso. Lorenzo de Zavala, su "Ensayo histórico" y la cuestión religiosa en México. México: FCE.

Velasco, M. (1967) El militarismo en la vida del mexicano hasta 1855. Estudios de historia moderna y contemporánea de México. México: UNAM.

Prensa:

El Federalista (México, 3 de febrero de 1872). 